\title{
UTILIZING AGENTS TO EXPLORE URBAN SHRINKAGE: A CASE STUDY OF DETROIT
}

\author{
Na Jiang \\ Andrew T. Crooks \\ Department of Computational Data Science \\ George Mason University \\ 4400 University Drive \\ Fairfax, VA 22030, USA \\ njiang8@gmu.edu \\ acrooks2@gmu.edu
}

\begin{abstract}
While the world's total urban population continues to grow, this growth is not equal. Some cities are declining, resulting in urban shrinkage which is now a global phenomenon. Many problems emerge due to urban shrinkage including population loss, economic depression, vacant properties and the contraction of housing markets. To explore this issue, this paper presents an agent-based model stylized on spatially explicit data of Detroit Tri-county area, an area witnessing urban shrinkage. Specifically, the model examines how micro-level housing trades impact urban shrinkage by capturing interactions between sellers and buyers within different sub-housing markets. The stylized model results highlight not only how we can simulate housing transactions but the aggregate market conditions relating to urban shrinkage (i.e., the contraction of housing markets). To this end, the paper demonstrates the potential of simulation to explore urban shrinkage and potentially offers a means to test polices to alleviate this issue.
\end{abstract}

Keywords: Urban Shrinkage, Housing Markets, Detroit, Agent-based Modeling, GIS

\section{INTRODUCTION}

For the first time in human history, more people are living in urban areas ( 4.2 billion people or $55 \%$ of the world's population) and this is expected to grow in the coming decades (United Nations, 2018). While the world's urban population continues to grow, this growth is not equal (Wei et al., 2017). Some cities are actually shrinking, and the list of shrinking cities expands every year and currently includes Berlin in Germany, Busan in South Korea, along with Detroit and Memphis in the United States. The causes of urban shrinkage have been the source of much debate but can be broadly attributed to a combination of factors relating to deindustrialization, suburbanization (i.e., urban sprawl), and demographic withdrawal (see: Couch et al., 2005; Großmann, et al., 2013; Reckien \& Martinez-Fernandez, 2011).

The result of shrinking cities, especially in and around the traditional downtown core of the city results in many problems, such as population loss, economic depression (due to loss in tax revenue), a growth in vacant properties, and the contraction of the land and housing markets. This is due broadly to deindustrialization which causes people to lose their jobs and unemployment rates to rise. Residents in such cities may therefore leave their current city in order to find employment opportunities in other areas. This results in a large number of properties in shrinking cities to be left vacant, when the population in a city declines. Significant amounts of vacant land and abandoned properties across an entire urban area are one of the key characteristics of a shrinking city (Deng \& Ma, 2015). Not only do these vacant (abandoned) 
properties potentially result in higher rates of crime (Shane, 2012), but also impacts the local economy, and contracts the local housing market (Martinez-Fernandez et al., 2012). For example, local governments collect less property tax revenue due to the vacant properties, and therefore have less money to allocate to public safety and infrastructure, which in turn potentially accelerates the population decline. In other words, the economic decline may worsen and the vacant properties may lead to the oversupply of stock within local housing markets. Therefore, it is rational to expect house prices to decrease (Xie et al., 2018) and if the population continues to decline, the local housing market may contract or collapse completely.

Under shrinkage, the contraction of the housing market can be explained at the macro-level through three processes: population loss, deindustrialization, and suburbanization. With respect to population loss, this leads to a decrease in demand for existing houses, which will lead to the depression of the housing market (Xie et al., 2018). Turing to the deindustrialization process, this will accelerate the contraction of the housing market as employees in certain industries (e.g., manufacturing) become unemployed and seek employment elsewhere which results in more houses in residential areas becoming empty (Reckien \& Martinez-Fernandez, 2011). Lastly, the third process associated with urban shrinkage, that of suburbanization, sees residents choosing new locations based on their own preferences and financial backgrounds rather than choosing to live in declining and potentially unsafe communities, which also causes the local housing market to contract (Power, 2001). Nevertheless, those factors view the contraction of the housing market from the macro-level. Hence, the motivation of this paper is to explore the housing market in a shrinking city from the micro-level, specifically based on individuals trading interactions. Therefore, an agent-based model is utilized as a tool to simulate and analyze a shrinking city's housing market. In the remainder of the paper, Section 2 introduces the study area and provides a literature review with respect to housing and land markets. Section 3 outlines our model while Section 4 presents the results of our simulation experiments. Finally, Section 5 concludes the paper and discusses areas of future study.

\section{BACKGROUND AND RATIONALE}

\subsection{A Shrinking Detroit}

The city of Detroit is the largest city in Michigan, located in the Great Lakes area of the United States, which has also been given the moniker the "Rust Belt region." There are many of stories which discuss the greatness of this city during the 1950s - were the automobile manufacturing sector rapidly expanded and its population reached peak (McDonald, 2014). However, the stories today often describe how over the last 60 years the city of Detroit has declined and shrunk and how a city growth can rapidly change into decline if it is focused on only one branch of economic production. One of the most significant phenomena that this city has witnessed is population loss, a decrease of over $60 \%$ in the last 60 years and $25 \%$ in the 10 years up to the last census of 2010 (Neill, 2015). With the increasing competition in the automobile manufacturing industry, deindustrialization swept through the city of Detroit and its surrounding regions (Rappaport, 2003). Large numbers of vacant properties and vacant land are now distributed to almost every corner of the city. There were approximately 60,000 vacant parcels of land and about 78,000 vacant structures, of which 38,000 were considered to be dangerous in 2014 (McDonald, 2014). This population decline resulted in the housing market shrinking from both the demand and supply sides (Poethig et al., 2017). In addition, the city of Detroit declared bankruptcy on July 18, 2013. Therefore, the city of Detroit is an excellent example of the shrinking city. In the sense that it is suffering population loss, deindustrialization, housing market contraction which resulted in city bankruptcy.

\subsection{Why Utilize Agent-based Modeling?}

This section discusses the rationale exploring urban shrinkage via agent-based modeling and related work related to the topic of land markets. Turning our reasons for utilizing agent-based modeling, the first is the ability of agent-based models to capture the hierarchical structure of systems from the bottom up, in the sense they focus on how individual interactions of entities (e.g., individuals buying and selling houses) at the micro-level allow us to capture more emergent phenomena at the macro-level (e.g., land markets). As 
such agent-based models can provide insights into the target phenomenon or system of interest, especially for complex systems that involve human-environmental interactions. In such systems, humans can impact the environment by their actions, and in turn the environment can impact the humans (e.g., An et al., 2005). Housing and land markets are excellent examples of human-environmental systems as the main components in such markets at the micro-level are buyers and sellers. They make their own decisions to trade or interact with each other and are impacted by the environment (e.g., economic and physical conditions) which can lead to a variety of housing market dynamics emerging overtime at the macro-level.

Secondly, agent-based modeling, unlike other modeling techniques, allows us to represent individuals as autonomous heterogenous entities, each with different attributes (e.g., income) which make decisions based on what they know about other agents as well as the environment in which they are located (Parker et al., 2003, Crooks et al., 2019). With respect to housing and land markets, this is an important consideration as all actors in the system (e.g., the buyers and seller) have different socioeconomic backgrounds, housing preferences, along with different bid and ask price strategies. Therefore through the implementation of an agent-based model these heterogeneous characteristics and unique behaviors can be represented and simulated.

With respect to modeling markets, Gode and Sunder (1993) were one of the first to demonstrate how agentbased models could be utilized to capture supply and demand. In their abstract model, traders were selected at random to buy and sell goods and through these interactions demonstrated how supply and demand curves observed in "real" world situations could emerge through simulation. Turning to land markets, Filatova et al. (2009) demonstrated how heterogenous agents with different ask and bid pricing behaviors could generate a land market in a stylized abstract environment while at the same time capturing urban growth which was validated against Alonso's (1964) theory of land rent within a monocentric city. Other researchers have also explored land markets emerging from the bottom up and how they impact land use within cities (e.g., Magliocca, et al., 2011; Torrens \& Nara, 2007). For example, Torrens and Nara (2007) simulated the demand and supply sides of a land market to explore urban gentrification in an area of Salt Lake City in Utah. However, while agent-based modeling of residential housing choices and land markets has started to show its potential as a valuable methodology to explore urban issues from the bottom up, no studies have explored land markets and urban shrinkage. Studies utilizing agent-based modeling to explore the urban shrinkage to date have mainly focused on land-use and residential dynamics (e.g., Schwarz et al., 2010; Haase et al., 2010) and not housing market dynamics. We would argue that capturing housing markets is essential for understanding urban shrinkage, as the contraction of housing markets is caused by population loss under a urban shrinking situation (Martinez-Fernandez et al., 2012). Hence, a model of urban shrinkage should capture not only residential dynamics but also trades (or lack of) within the housing market. Therefore, an agent-based model stylized on spatially explicit data is presented in this paper to simulate the urban shrinkage in the Detroit Tri-county area in order to explore how micro-level housing trades impact on macro-level shrinkage by capturing trades between sellers and buyer within different dynamic sub-housing markets

\section{MODEL DESIGN}

\subsection{Objective}

In this work, an agent-based model is built to capture urban shrinkage through the simulation of a housing market stylized on the Detroit Tri-county area which is displayed in Figure 1. In what follows we provide a brief description of the model; however, for interested readers a more detailed description of the model following the Overview, Design concepts, and Details (ODD) (Grimm et al., 2006) protocol along with the source code and data needed to run the model can be found at: http://bit.ly/UrbanShrinkage. We do this to aid replication and for others to extend if they see fit.

As noted in Sections 1 and 2, urban shrinkage is impacted by housing and land markets and while land markets in general have been modeled, they have not been applied to explore urban shrinkage. The model 
presented in this paper focuses on housing trades or transactions within various housing submarkets within the Detroit Tri-County area. It should be noted, however, that we don't model other dynamics of the economy as a whole which might affect urban shrinkage because this would become an overwhelming endeavor and beyond the scope of this current paper, which we will revisit in Section 5 (however, variables within the model do capture employment, as will be discussed Section 3.2). The whole Detroit Tri-County area can be divided into three sub-housing markets which includes downtown, city suburban, and far suburban housing markets as depicted in Figure 1. Both the downtown area and suburban areas are within Wayne County; the differences between these areas is that the downtown area is defined by City of Detroit opportunity zone data, while the suburban area excludes the downtown area (City of Detroit Open Data Portal, 2019). For the rest of the study area we call it "far suburban", which is not part of Wayne County and is comprised of Oakland and Macomb counites and its distance to downtown Detroit area is much further. In order to model, simulation and experiment with the housing market, we chose NetLogo, as it has capabilities to handle the spatial data needed to build this stylized model and allows for rapid model prototyping. However, there are constraints to the platform specifically relating to scalability (both in terms of agents and spatial resolution). The temporal scale in this model is notionally considered to be a one-year time step.

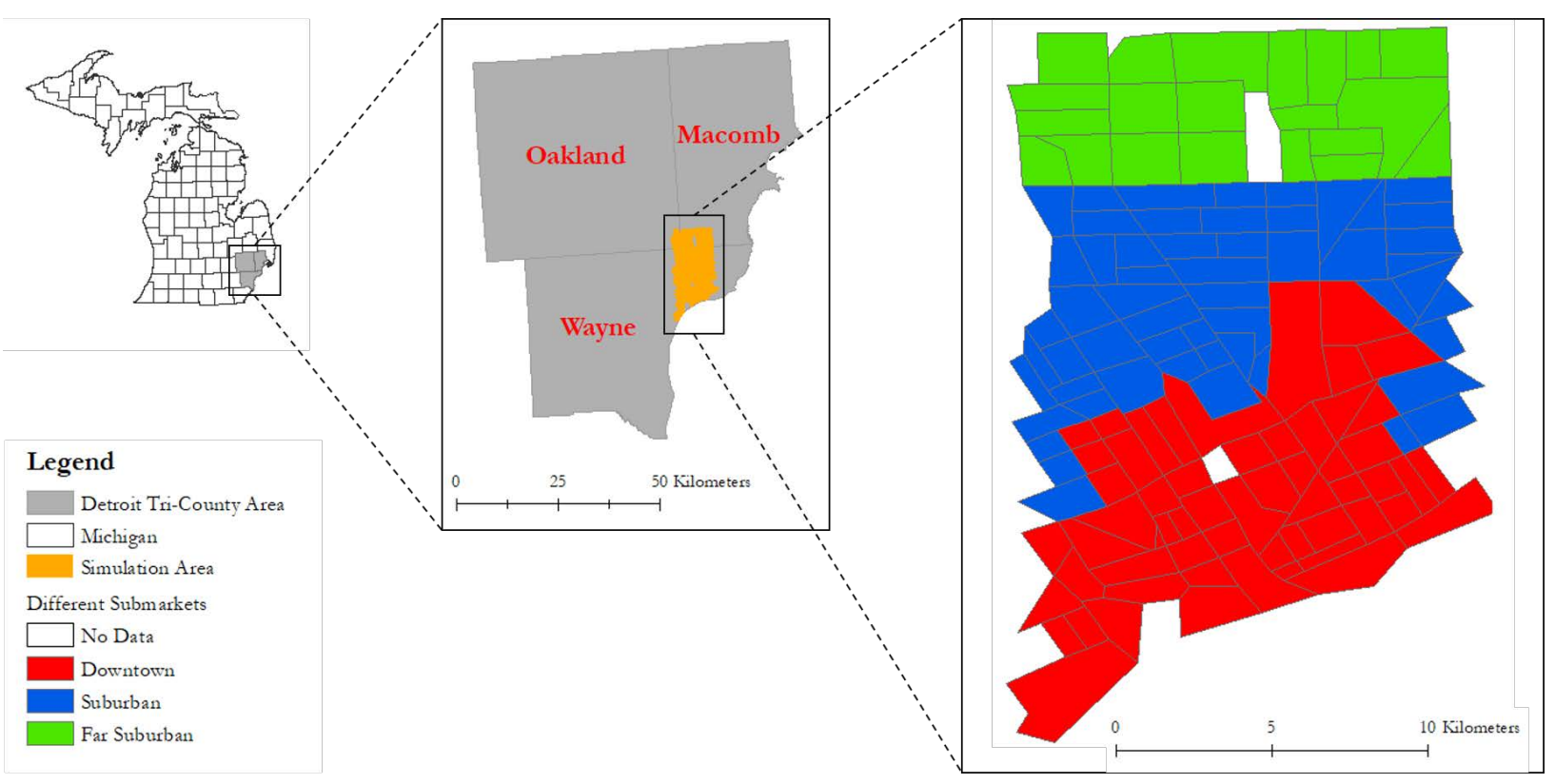

Figure 1: Detroit Tri-County Area (middle) and Simulation Area (right).

\subsection{Model Components}

\subsubsection{Model Initialization and Input Parameters}

The initialization of the model is based on socioeconomic and geo-spatial data of the study area. The socioeconomic data (e.g., income, employment status, house prices) comes from the American Community Survey (2010) for each census tract in the study area. Before applying this data to initialize the number of household agents within our simulation, the data was preprocessed using Python to allow for efficient input into the NetLogo platform. Due to the computational constrains of the NetLogo, simulations which entail a large number of agents are computationally intensive and time-consuming, therefore we only represent $1 \%$ (i.e., 1278) of the total number of households within the study area. As the socioeconomic data is aggregated, we only use average house prices along with upper and lower quartiles within each census tract; therefore, in order to assign houses prices we use this distribution (referred to Balance in the model code). Specifically, the total amount of agents is divided by the balance, and an equal number of agents are then assigned a house price by adding a random number within the upper quartile range to the average, while 
the other half are assigned a house price by a random number between lower quantile and the average. For example, if the average house price was 50, and the upper and the lower quartiles were 75 and 25 respectively, and we had two agents, one agent would be given a value of $50+$ a random number between 50 and 75. While the other agent would be given $50-$ a random number between 25 and 50 . We do this to ensure we get a range of house prices within a census tract. Another input parameter is the diffusion rate $(D R)$ which controls the agents' movements to other submarkets, buyer agents can diffuse to any of the submarkets, while seller agents can diffuse outside its submarket once they complete a transaction and become a buyer (the default setting being 1, that is household agents have the ability to move out of their current submarket if they desire to). This diffusion rate was inspired by Patel et al. (2012) who used the same concept to explore residential movment but also is akin to what we observe with urban growth, whereby residents in inner cities move to more suburban locations. There are also two other user settable input partamters; one is the economic growth rate (which is disscussed in Section 3.2.3) and the demand and supply conditions ( $D$-S parameter) which basically controls the ratio of buyers and sellers. The model generates sellers based on the number of buyers, for instance, when set to defalut (i.e., 1) and the number of buyer is set to 100 , the model generates $100 * 1$ sellers, which indicats equal demand and supply. Table 1 provides an overview of the model parameters along with their default values.

Table 1: Model Parameters.

\begin{tabular}{|c|c|l|l|}
\hline Parameters & $\begin{array}{c}\text { Default } \\
\text { Value }\end{array}$ & \multicolumn{1}{|c|}{ Description } & Reference \\
\hline Balance & 50 & $\begin{array}{l}\text { Controls the initialization house price of households; } \\
\text { the default value indicates house price are generated } \\
\text { based on normal distribution }\end{array}$ & $\begin{array}{l}\text { Author } \\
\text { estimation }\end{array}$ \\
\hline $\begin{array}{c}\text { Diffusion Rate } \\
\text { (DR) }\end{array}$ & 1 & $\begin{array}{l}\text { Controls the household movement to another } \\
\text { neighborhood; the default value allows households to } \\
\text { diffuse other neighborhoods }\end{array}$ & $\begin{array}{l}\text { Patel et al. } \\
\text { (2012) }\end{array}$ \\
\hline $\begin{array}{c}\text { Economic Rrowth } \\
\text { Rate }\end{array}$ & $-4 \%$ & $\begin{array}{l}\text { Controls the macro economic environment; the default } \\
\text { value indicates negative growth }\end{array}$ & $\begin{array}{l}\text { Author } \\
\text { estimation }\end{array}$ \\
\hline D-S & 1.0 & $\begin{array}{l}\text { Demand and supply, can be controlled by the user; the } \\
\text { default value indicates equal demand and supply }\end{array}$ & $\begin{array}{l}\text { Author } \\
\text { estimation }\end{array}$ \\
\hline
\end{tabular}

Table 2: Household Agent Attributes.

\begin{tabular}{|c|l|l|}
\hline Attribute & \multicolumn{1}{|c|}{ Description } & \multicolumn{1}{c|}{ Reference } \\
\hline ID & Unique ID for households & Filatova et al. (2009) \\
\hline HNT & $\begin{array}{l}\text { Household neighborhood type that indicated which } \\
\text { sub-housing market is household located }\end{array}$ & Detroit Open Data Portal (2018) \\
\hline HPOLY & Polygon ID indicated which polygon is household on & Author estimation \\
\hline HINCOME & Income of the household & $\begin{array}{l}\text { Patel et al., (2012), Torrens and } \\
\text { Nara (2007) }\end{array}$ \\
\hline HBUDGET & Budget for annual housing cost & Filatova et al. (2009) \\
\hline BUYER? & Boolean value, if true, buyer household & Filatova et al. (2009) \\
\hline BIDPRICE & Only associate with buyer households & Filatova et al. (2009) \\
\hline SELLER? & Boolean value, if true, seller household & Filatova et al. (2009) \\
\hline ASKPRICE & Only associate with seller households & Filatova et al. (2009) \\
\hline EMPLOYED? & Boolean value, if true, household has job, else, no jobs & Patel et al. (2012) \\
\hline TRADE? & Boolean value, if true, indicates household will trade & Filatova et al. (2009) \\
\hline
\end{tabular}

\subsubsection{Agents}

The main agent in this model are households who live in Detroit the Tri-County area. For the purpose of compressing experiments period and simplification as mentioned in Section 3.2.1, we use 1 agent is used to represent 100 households. Agents comprise of various attributes that result in a heterogenous population. 
Except HPOLY, the remainder of the agents' attributes are added based on relevant literature, which is summarized by Table 2. Agents vary from their characteristics (e.g., ID, HNT) and financial backgrounds (e.g., HINCOME). Furthermore, agents can be categorized into two types buyer and seller households and they are all goal-oriented. Buyers have one goal which is finding an affordable house by proposing a bid price to sellers. On the other hand, sellers will post the asking price and maximize the profits from the trades. The key attribute of the household is their incomes (HINCOME), which provides the heterogeneity within the world and is updated as the simulation processes, which is described in 3.2.2. There are several models that have used income to control residential decision making (e.g., Alonso, 1964; Patel et al., 2012). Accordingly, in this model, each household will make decisions based on their income (HINCOME) status, which is to either stay or leave the current location. During each time step of the simulation, households will check if they can still afford their current living location based on their annual budgets (HBUDGET) calculated from their income, also this income attribute informs the house trading process.

Before all trades happen, all households will check their affordability on their current living sites by comparing their annual budget (HBUDGET) and the minimum housing cost (which we describe below). To check this, all households will set their budgets (HBUDGET), which represents $34 \%$ of their income (HINCOME) and can be used on annual house fees including property tax, annual maintenance and etc. (Bourne, 2018). The minimum housing cost includes property tax, house's maintenance fee and mortgage payment. To calculate the minimum cost, three percentage numbers are referenced including $1.52 \%$ of house price for the property tax, $1.3 \%$ of the house price for the annual maintenance fee and $4.54 \%$ of house price for mortgage payment (Brinkley-Badgett, 2017; Pant, 2019; ValuePenguin, 2019). Hence, we set $7.38 \%$ of the house price as the minimum cost indicates the lowest annual cost for a house. Households whose minimum housing cost exceeds the annual budget become buyers. They set the bid prices (BIDPRICE) 2.5 times of their gross income to purchase a new house from sellers. (CNNMoney, 2015). If their bid prices are greater than the average house price of a certain submarket, they will enter that submarket and find affordable houses. If not, they will continually move until they find affordable submarkets to purchase houses. After buyers' movements, the sellers will set the ask price based on the house price and find a buyer to complete the trade. Sellers have the goal to maximize the profits from the trade, so they will choose the buyer with the best bid price. After the trade is completed, the trade will be registered by the housing market. A Buyer's household decision-making process is displayed by Figure 2 .

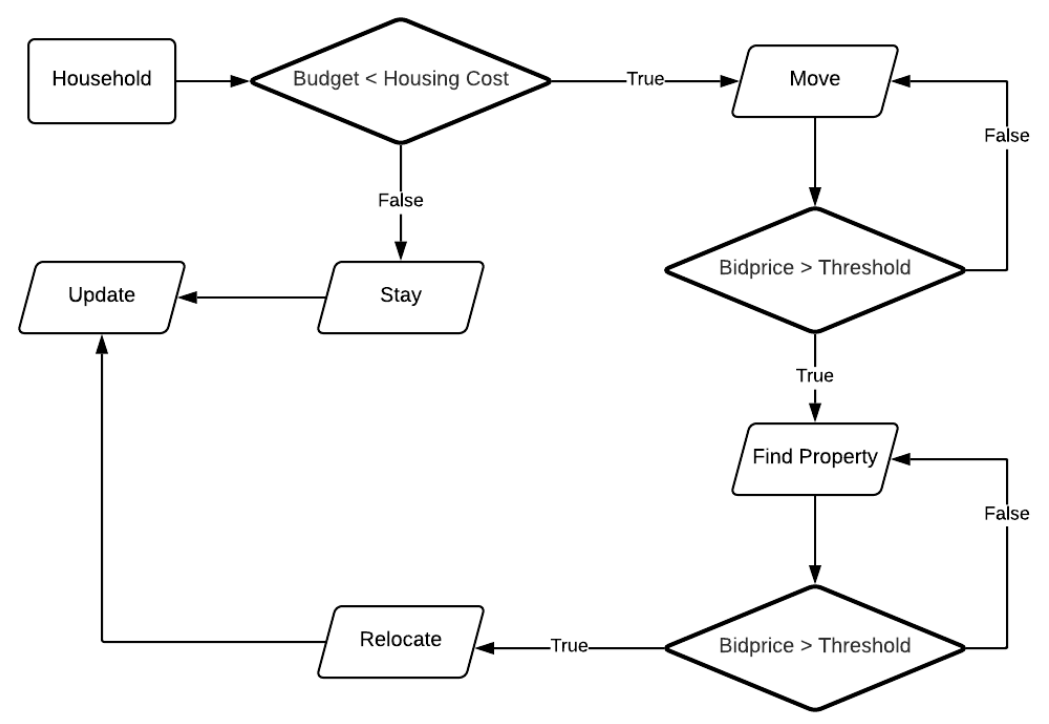

Figure 2: Decision Making Process. 


\subsubsection{Environment}

The other component of this model is the environment, which contains three different elements: 1) Geospatial; 2) Artificial housing market comprising three different submarkets: Downtown, Suburban and Far Suburban; and finally 3) the Economic environment. The geo-spatial environment provides a geographic boundary of the whole simulation area and the boundaries of the three sub-housing markets. In addition, the geo-spatial environment provides a physical environment for all agents moving around. All households agents use this environment to locate themselves in different sub-housing markets and use the locations to interact with housing market environment.

As for the artificial housing market, this is a hidden environment that can capture the trades between buyer and seller households. There are several models that have used income to control residential decision making (e.g., Alonso, 1964; Patel et al., 2012), and this model is no different. Each household will make decisions based on their income (HINCOME) status, which is to either stay or leave the current location. Although the decision-making is always a complex procedure (Crooks et al., 2019), within the model a relative simple process is implemented as discussed in Section 3.2.2.

The economic environment is the invisible hand in this model, which will impact the income of each household and the house price (Patel et al., 2012). As shown by equation (1), the income dynamics are based on economic growth (which is a user settable parameter and by default is to $-4 \%$, which was chosen due to economic conditions seen within the Detroit region (Neill, 2015)) and the agents' employment status. $I_{t}+1$ is the income at the time ${ }_{t+1}, I_{t}$ is the income at time $t$ and $G$ is the economic growth. The $\alpha$ represents the employment status (e.g., 0 represents unemployed, 1 represents employed). As we are only modeling households we assume if one agent within the household has a job, $\alpha$ will be the $\ln$ of $G$ 's absolute value, if not, it will be -0.1 .

$$
I_{t+1}=I_{t}(G+1)+\alpha * I_{t}
$$

During the simulation, the house prices are also affected by changes to the economic growth $(G)$ rate. However, the impact of $G$ will vary in different submarkets. Our rationale for this as discussed in Section 1 , is that there are various processes that lead to urban shrinkage (especially that of suburbanization) which impact different submarkets differently. The house prices are updated by the equation $(2), H_{t+l}$ represents house price at time $\mathrm{t}+1$ after updating, $H_{t}$ reflects the original house price at time $t, G$ is the economic growth.

$$
H_{t+1}=\left\{\begin{array}{lr}
H_{t}(1-0.25 G), \quad \text { Downtown } \\
H_{t}(1+0.5 G), \quad \text { City Suburban } \\
H_{t}(1-0.5 G), \quad \text { Far Suburban }
\end{array}\right.
$$

\subsection{Model Dynamics}

The sequences of all function events in this model are displayed by the UML diagram in Figure 3, which demonstrates the model flow, dynamic and interaction among the different components of the model. As mentioned above, households use the relative locations from the spatial environment to locate themselves in different sub-housing markets. Both buyers and sellers use their locations to gather information related to the trades from the sub-housing market.

\section{RESULTS}

In this section, we first discuss efforts made for verification of the model in Section 4.1 before demonstrating in Section 4.2 different market demand and supply scenarios in order to highlight how our model can reflect residential housing markets and the resulting urban shrinkage from the bottom up. For the verification results, one-time experimental results are reported. However, for the scenario simulations 
(Section 4.2), each scenario experiment was simulated 10 times and the average of all experimental outputs is given.

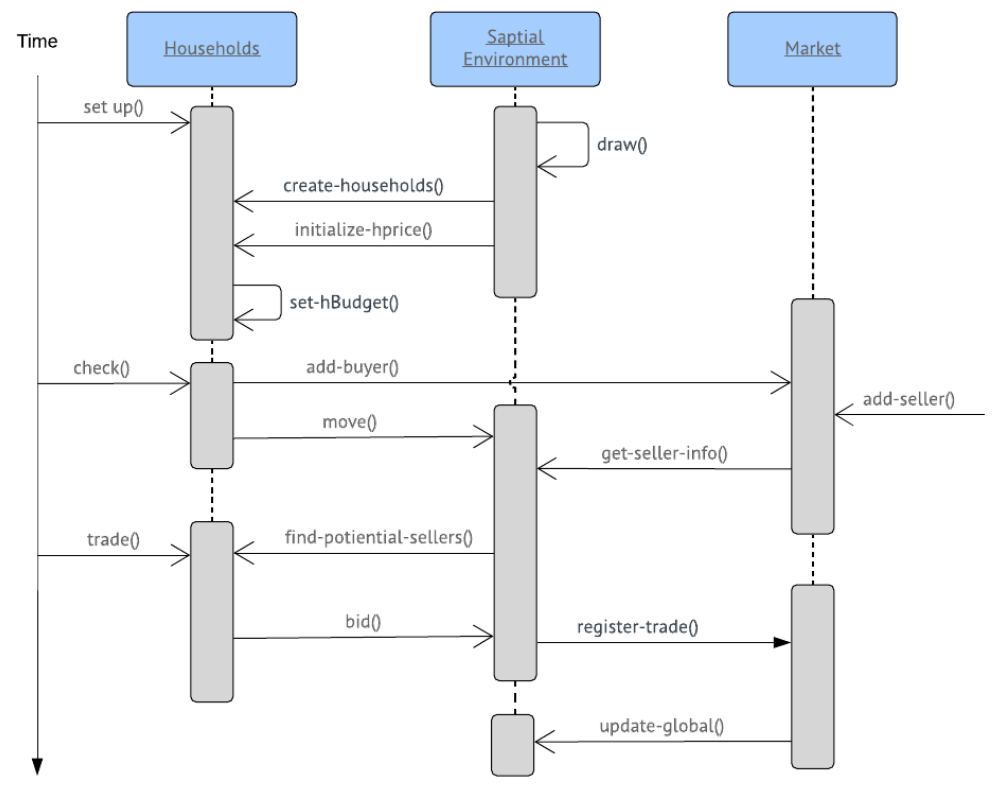

Figure 3: UML of the Model.

\subsection{Verification}

Verification is the process of checking that the model matches its design (Crooks et al., 2019). In this study, verification of the model was performed by conducting code walkthroughs and extreme value (parameter) testing to ensure the model was working as designed. These tests insured that we made no logical errors in the translation of the model into code, and that there were no programming errors. An example of extreme value testing is presented in Table 3. In this experiment when the diffusion rate $(D R)$ is set to either 0 or 1 . 0 indicates that households can only choose homes within the same submarket that they are currently living in, while 1 allows households to move to different submarkets if so desired. While Balance controls the initial house price distributions (as discussed in Section 3.2.1), when Balance is set at 0, more houses are initialized with lower than average prices, while Balance is set to 100 results in more higher value houses being initialized.

As shown in Table 3 when $D R$ is set to 0 , the number of households stays the same as the initialization number as the agents cannot move to different submarkets. However, when $D R$ is set to 1, the number of households varies drastically from when the model is initialized. Hence, the $D R$ parameter works as expected, which impacts the households' movement between the different submarkets. As for Balance extreme values, when set at 0 , the average price (AVG) is 55.42, which is lower than the default setting of 80.48 when Balance is set to 50. When Balance is set at the highest value, the average house price is 106.05. Therefore, we are confident that Balance adds the variations to the house price distributions within our stylized model. After carrying out these tests, we feel confident that the model behaves as it is intended and matches its design.

\subsection{Simulation Scenarios}

In order to explore how our model can capture market behavior as it potentially relates to urban shrinkage, we now present several simulation scenarios of different demand and supply conditions for a period of five time steps and we run each scenario for 10 times and in what follows we describe the average results. We chose five years as this avoids longer term economic environmental impacts on the housing market. 
However, as we have made the model available (see Section 3), readers can run the simulation for longer if they see fit and observe the results. To control the demand and supply, we only changed the $D-S$ parameter in the model and kept all other parameters at their default values. Three different scenarios were simulated to explore how the demand and supply condition impacts average house prices in the different submarkets: 1) equal demand and supply; 2) demand exceeds supply; 3) supply exceeds demand. Table 4 shows the initial number of agents in each submarket for different D-S settings along with the final numbers after five time steps. As can be seen altering the $D$-S parameter the number of households in the downtown area decreases while the suburbs all see an increase in households.

Table 3: Verification Results (Note 1 Agent is Representative of 100 Households).

\begin{tabular}{|c|c|c|c|c|c|c|}
\hline Parameters & Description & $\begin{array}{l}\text { Min, } \\
\text { Max }\end{array}$ & $\begin{array}{c}\text { AVG } \\
\text { House }\end{array}$ & \multicolumn{3}{|c|}{ Households in Each Sub-Housing Market } \\
\hline \multirow{7}{*}{$\begin{array}{l}\text { Diffusion } \\
\text { Rate (DR) }\end{array}$} & \multirow{7}{*}{$\begin{array}{c}\text { Control the } \\
\text { household } \\
\text { movement to } \\
\text { another submarket }\end{array}$} & \multirow{4}{*}{0} & \multirow{4}{*}{81.05} & \multicolumn{2}{|c|}{ Initialization } & Results \\
\hline & & & & Downtown & 446 & 446 \\
\hline & & & & Suburban & 502 & 502 \\
\hline & & & & Far Suburban & 330 & 330 \\
\hline & & \multirow{3}{*}{1} & \multirow{3}{*}{80.98} & Downtown & 446 & 360 \\
\hline & & & & Suburban & 502 & 579 \\
\hline & & & & Far Suburban & 330 & 339 \\
\hline \multirow{9}{*}{ Balance } & \multirow{9}{*}{$\begin{array}{c}\text { Control the initial } \\
\text { house prices of } \\
\text { households }\end{array}$} & \multirow{3}{*}{0} & \multirow{3}{*}{55.42} & Downtown & 446 & 417 \\
\hline & & & & Suburban & 502 & 531 \\
\hline & & & & Far Suburban & 330 & 330 \\
\hline & & \multirow{3}{*}{50} & \multirow{3}{*}{80.48} & Downtown & 446 & 426 \\
\hline & & & & Suburban & 502 & 521 \\
\hline & & & & Far Suburban & 330 & 331 \\
\hline & & \multirow{3}{*}{100} & \multirow{3}{*}{106.05} & Downtown & 446 & 318 \\
\hline & & & & Suburban & 502 & 620 \\
\hline & & & & Far Suburban & 330 & 340 \\
\hline
\end{tabular}

Table 4: Different Simulation Scenarios Initialization Numbers and Average Results (Note 1 Agent is Representative of 100 Households).

\begin{tabular}{|c|c|c|c|c|c|}
\hline D-S & Description & Initial Number of & \multicolumn{3}{|c|}{ AVG Number of Households in Each Submarket } \\
\hline \multirow{4}{*}{0.5} & \multirow{4}{*}{$\begin{array}{l}\text { Demand } \\
\text { exceeds } \\
\text { supply }\end{array}$} & \multirow{4}{*}{108,54} & & Number & Final Number \\
\hline & & & Downtown & 446 & 427 \\
\hline & & & Suburban & 502 & 515 \\
\hline & & & Far Suburban & 330 & 335 \\
\hline \multirow{3}{*}{1.0} & \multirow{3}{*}{$\begin{array}{c}\text { Equal } \\
\text { demand and } \\
\text { supply }\end{array}$} & \multirow{3}{*}{107,107} & Downtown & 446 & 430 \\
\hline & & & Suburban & 502 & 514 \\
\hline & & & Far Suburban & 330 & 333 \\
\hline \multirow{3}{*}{1.5} & \multirow{3}{*}{$\begin{array}{l}\text { Supply } \\
\text { exceeds } \\
\text { demand }\end{array}$} & \multirow{3}{*}{112,168} & Downtown & 446 & 426 \\
\hline & & & Suburban & 502 & 519 \\
\hline & & & Far Suburban & 330 & 330 \\
\hline
\end{tabular}

Building on Table 4, Figure 4 shows the three scenarios for the number of households for each submarket. In all three scenarios, downtown shrinkage can be observed in terms of the decreasing number of households from year 0 to 5 . Households are generally choosing to relocate in suburban and far suburban areas leading to a decline in downtown populations; however, a small number of households did move to 
the downtown area in one scenario at year 2, that of when demand exceeded supply (as can be seen in Figure 4A) which can be explained as there are a limited number of houses available in suburban and far suburban submarkets.

\section{CONCLUSION AND DISCUSSION}

Urban shrinkage itself and problems brought by it have drawn a lot of attention globally; however, few efforts have been made to explore this global phenomenon from the modeling and simulation approach. This paper has demonstrated our initial foray into exploring urban shrinkage through housing markets stylized upon the Detroit Tri-county area. Results from the model show that through the buying and selling of houses can lead to a decline in households within the downtown area. This result has implications with respect to urban shrinkage, as discussed in Section 1. A decline in households leads to less tax revenue and therefore limits a city's ability to provide services which in turn can lead to more urban decline.

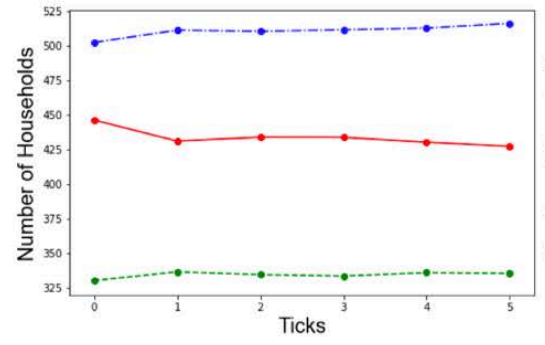

(a)

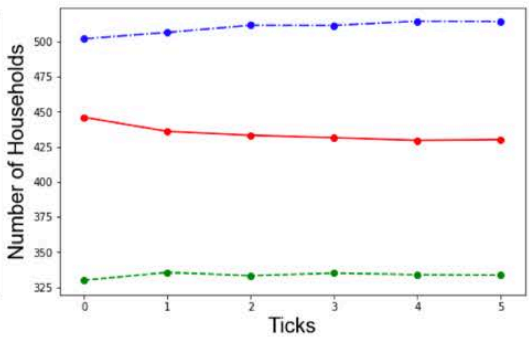

(b)

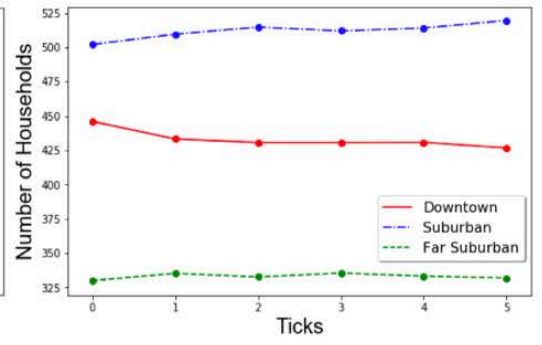

(c)

Figure 4: Average Results where: (a) demand exceeds supply; (b) equal demand and supply; (c) supply exceeds demand for each different housing sub market.

All models have their limitations and there is always room for improvement and this is also the case for this model presented in this paper. Specifically, this paper only explored the buying and selling of properties; however, as we noted in the introduction (Section 1), urban shrinkage is a complex issue and we don't specifically model the economic environment endogenously (rather we have it as an input parameter in terms of economic growth rate). Future work should therefore better capture how changes in employment and demographics impact on residents' ability to stay in an area and their preferences for certain types of neighborhoods. However, this would be a large undertaking and most agent-based models like the ones cited in Section 2 only look at one aspect (i.e., subsystem) such as the land market rather than the entire urban system itself (Crooks et al., 2019).

Furthermore, for sake of simplicity, our model only allowed agents to relocate within one of the three housing submarkets; however, we know that people faced with unemployment might move out of the area entirely. In addition, urban shrinkage is related to other macro issues such as structural social-economic factors and urban sprawl. These should therefore be explored in future work and as such could be compared to data from the census. Of course the model could be also extended to represent more types of housing stock (e.g., apartments, single family homes) which could be sourced from the American Community Survey or local government property records along with home sales data. We chose not to go this route here as the purpose of the model was to act as a prototype to explore how urban shrinkage might emerge from the bottom up through the interactions of buying and selling houses. Even with these limitations and areas of further work we believe this paper has proved how agent-based modeling integrated with geospatial data provides a promising method to explore urban shrinkage and if developed further potentially offers a means to test polices to alleviate this issue. 
Jiang and Crooks

\section{REFERENCES}

Alonso, W. 1964. Location and Land Use: Toward a General Theory of Land Rent, Cambridge, Mass. Harvard University Press

American Community Survey. 2010. "American Community Survey (ACS)" https://www.census.gov/programs-surveys/acs. Accessed April. 10, 2019.

An, L., M. Linderman, J. Qi, A. Shortridge, and J. Liu. 2005. "Exploring Complexity in a HumanEnvironment System: An Agent-Based Spatial Model for Multidisciplinary and Multiscale Integration," Annals of the Association of American Geographers vol. 95, pp. 54-79.

Benenson, I., I. Omer, and E. Hatna. 2002. "Entity-Based Modeling of Urban Residential Dynamics: The Case of Yaffo, Tel Aviv," Environment and Planning B: Planning and Design vol. 29, pp. 491-512.

Bourne, R. 2018. Government and the Cost of Living: Income-Based vs. Cost-Based Approaches to Alleviating Poverty. CATO INSTITUTE. Available via https://www.cato.org/publications/policyanalysis/government-cost-living-income-based-vs-cost-based-approaches. Accessed May. 10, 2019

Brinkley-Badgett, C. 2017. Comparing Average Property Taxes for All 50 States and D.C.. USA TODAY. Available via https:/www.usatoday.com/story/money/personalfinance/2017/04/16/comparingaverage-property-taxes-all-50-states-and-dc/100314754/. Accessed May. 10, 2019

City of Detroit Open Data Portal 2019, “Opportunity Zones". https://data.detroitmi.gov/datasets/opportunity-zones. Accessed May. 10, 2019

CNNMoney 2015. "Buying a Home in 10 Steps" https://money.cnn.com/pf/money-essentials-homebuying/index.html. Accessed Jan. 10, 2019

Crooks, A.T., Malleson, N., Manley, E. and Heppenstall, A.J. 2019. Agent-based Modelling and Geographical Information Systems: A Practical Primer, London, UK. Sage.

Couch, C., J. Karecha, H. Nuissl, and D. Rink. 2005. "Decline and Sprawl: An Evolving Type of Urban Development - Observed in Liverpool and Leipzig," European Planning Studies vol. 13, pp. 117-136.

Deng, C., and J. Ma. 2015. "Viewing Urban Decay from the Sky: A Multi-Scale Analysis of Residential Vacancy in a Shrinking US City," Landscape and Urban Planning vol. 141, pp. 88-99.

Filatova, T., D. Parker, and A. Van der Veen. 2009. “Agent-Based Urban Land Markets: Agent's Pricing Behavior, Land Prices and Urban Land Use Change," Journal of Artificial Societies and Social Simulation vol. 12, article 3.

Gode, D. K., and S. Sunder. 1993. "Allocative Efficiency of Markets with Zero-Intelligence Traders: Market as a Partial Substitute for Individual Rationality," Journal of Political Economy vol.101(1), pp. $119-137$.

Grimm, V., U. Berger, F. Bastiansen, S. Eliassen, V. Ginot, J. Giske, J. Goss-Custard, T. Grand, S. K. Heinz, G. Huse, A. Huth, J. U. Jepsen, C. Jørgensen, W. M. Mooij, B. Müller, G. Pe’er, C. Piou, S. F. Railsback, A. M. Robbins, M. M. Robbins, E. Rossmanith, N. Rüger, E. Strand, S. Souissi, R. A. Stillman, R. Vabø, U. Visser, and D. L. DeAngelis. 2006. "A Standard Protocol for Describing Individual-Based and Agent-Based Models," Ecological Modelling vol. 198, pp. 115-126.

Großmann, K., M. Bontje, A. Haase, and V. Mykhnenko. 2013. "Shrinking Cities: Notes for the Further Research Agenda," Cities vol. 35, pp. 221-225.

Haase, D., Lautenbach, S., and Seppelt, R. 2010. "Modeling and Simulating Residential Mobility in a Shrinking City using an Agent-based Approach," Environmental Modelling \& Software vol. 25, pp. 1225-1240.

Magliocca, N., E. Safirova, V. McConnell, and M. Walls. 2011. "An Economic Agent-based Model of Coupled Housing and Land Markets (CHALMS)," Computers, Environment and Urban Systems, vol 35(3), pp. 183-191. 
Martinez-Fernandez, C., Audirac, I., Fol, S., and Cunningham-Sabot, E. (2012). "Shrinking Cities: Urban Challenges of Globalization," International Journal of Urban and Regional Research, vol. 36, pp. 213225.

McDonald, J. F. 2014. "What Happened to and in Detroit?," Urban Studies vol. 51, pp. 3309-3329.

Neill, W. J. V. 2015. "Carry on Shrinking?: The Bankruptcy of Urban Policy in Detroit," Planning Practice \& Research vol. 30, pp. 1-14.

Pant, P. 2019. How Much You Should Budget for Home Maintenance. The Balance. Available via https://www.thebalance.com/home-maintenance-budget-453820. Accessed Nov 10, 2019

Parker, D. C., S. M. Manson, M. A. Janssen, M. J. Hoffmann, and P. Deadman. 2003. "Multi-Agent Systemsfor the Simulation of Land-Use and Land-Cover Change: A Review," Annals of the Association of American Geographers vol. 93, pp. 314-337.

Patel, A., A. Crooks, and N. Koizumi. 2012. "Slumulation: An Agent-Based Modeling Approach to Slum Formations," Journal of Artificial Societies and Social Simulation vol. 15, article 2.

Poethig, E. C., J. Schilling, L. Goodman, B. Bai, J. Gastner, R. Pendall, and S. Fazili. 2017. "The Detroit Housing Market: Challenges and Innovations for a Path Forward," Urban Institute, Washington DC. 2017, pp. 92.

Power, A. 2001. "Social Exclusion and Urban Sprawl: Is the Rescue of Cities Possible?," Regional Studies, vol. 35 , pp. $731-742$.

Rappaport, J. 2003. "U.S. Urban Decline and Growth, 1950 to 2000," Economic Review vol. 88, pp. 15-44.

Reckien, D., and C. Martinez-Fernandez. 2011. "Why Do Cities Shrink?” European Planning Studies vol. 19, pp. 1375-1397.

Schwarz, N., D. Haase, and R. Seppelt. 2010. "Omnipresent Sprawl? A Review of Urban Simulation Models with Respect to Urban Shrinkage," Environment and Planning B: Planning and Design vol. $37(2)$, pp. 265-283.

Shane, J. M. 2012. Abandoned Buildings and Lots. Washington, D.C., U.S. Department of Justice.

Torrens, P. M., and A. Nara. 2007. "Modeling Gentrification Dynamics: A Hybrid Approach" Computers, Environment and Urban Systems vol. 31, pp. 337-361.

United Nations. 2018. "2018 Revision of World Urbanization Prospects," Department of Economic and Social Affairs, New York, NY, Available at https:/population.un.org/wup/.

ValuePenguin. 2019. "Michigan Mortgage Rates for June 2019”. https://www.valuepenguin.com/mortgages/michigan-mortgage-rates. Accessed Nov 10, 2019

Wei, Y. D., H. Li, and W. Yue. 2017. "Urban Land Expansion and Regional Inequality in Transitional China," Landscape and Urban Planning vol. 163, pp. 17-31.

Xie, Y., H. Gong, H. Lan, and S. Zeng. 2018. "Examining Shrinking City of Detroit in the Context of Socio-spatial Inequalities," Landscape and Urban Planning vol. 177, pp. 350-361.

\section{AUTHOR BIOGRAPHIES}

NA JIANG is a Ph.D. student in Computational Social Science (CSS) program at George Mason University (GMU). He holds a Master of Science and Bachelor of Science from Eastern Michigan University. His research interests relate to urban issues utilizing geographical information science (GIS) and agent-based modeling (ABM). His email address njiang8@gmu.edu.

ANDREW CROOKS is an Associate Professor of Computational Social Science within the Department of Computational and Data Sciences at GMU. His research interests relate to exploring and understanding of the natural and socio economic environments using GIS and ABM methodologies. His email address and website are acrooks2@gmu.edu and http://gisagents.org. 